\title{
Teses e dissertações do Programa de Pós-Graduação em História, Política e Bens Culturais do CPDOC/FGV defendidas em 2010
}

Olhares sobre a Restauração da Igreja Nossa Senhora do Carmo da Antiga Sé Juliana Lages Sarinho Defesa: 04/03/2010 - Mestrado Profissional

Banca: Letícia Borges Nedel (orientadora), Marly da Silva Motta (CPDOC/FGV), Andréia de Lacerda Pessoa Borde (FAU/URFRJ), Lucia Maria Lippi de Oliveira

Resumo: O trabalho examina o processo de construção de memórias relacionadas ao bem patrimonial, a partir do estudo de caso da restauração da Igreja Nossa Senhora do Carmo da antiga Sé, realizada para as comemorações do bicentenário de chegada da Família Real ao Brasil, organizada pela Prefeitura da Cidade do Rio de Janeiro em 2008. Mediante a realização de entrevistas semi-diretivas com atores sociais ligados à igreja e aos órgãos responsáveis pelas obras de restauração, além do recurso à documentação gerada para e em função das obras, foram apontadas as escolhas, conflitos e negociações em jogo no planejamento e na execução do projeto. Pôde-se constatar ainda, na análise do processo de restauração, a percepção polissêmica desse bem patrimonial, na medida em que esteve sujeito à introdução de novos usos e significados ligados a práticas museais e turísticas que acompanham sua recuperação arquitetônica. Finalmente, o trabalho ressalta a necessidade de ampliar os estudos sobre patrimônio, estendendo-se a análise da produção da memória social ao âmbito da recepção, pelos diferentes grupos sociais, dos bens que pretendem representar e materializar uma memória comum. 
História, Memória e Patrimônio da Escola Militar do Realengo

Claudius Gomes de Aragão Viana

Defesa: 16/03/2010 - Mestrado Profissional

Banca: Celso Corrêa Pinto de Castro (orientador), Fernando da Silva

Rodrigues (Arquivo. Histórico do Exército), Angela Maria de Castro Gomes (CPDOC/FGV), Letícia Borges Nedel (CPDOC/FGV).

Resumo: Esta dissertação analisa a influência das instituições militares, particularmente a Escola Militar, no período de 1912 a 1944, na configuração urbana de Realengo, subúrbio do município do Rio de Janeiro. Tendo como principal corpus documental os relatórios do Ministério da Guerra e a legislação pertinente, são estabelecidos marcos históricos para análise do processo de transformação da antiga zona rural do município em uma área militar, enfatizando os impactos que incidiram sobre a região em decorrência da transferência da sede da Escola Militar do Brazil, da Praia Vermelha para Realengo. Preliminarmente, são identificadas as primeiras unidades militares que ocuparam a região, sendo estabelecidas conexões entre o funcionamento dessas organizações, a constituição do seu patrimônio e o desenvolvimento urbano de Realengo. Para a contextualização, também são apresentadas as sedes ocupadas pela Escola Militar ao longo do século XIX e as circunstâncias que motivaram sua saída da Praia Vermelha no início do século XX. O recorte temporal se inicia no período compreendido entre o início do século XIX, quando as chamadas terras realengas foram doadas à Câmara da cidade do Rio de Janeiro por D. João VI; atravessa o século $\mathrm{XX}$, quando se consolidaram o patrimônio da Escola Militar em Realengo e a urbanização do bairro; e chega aos dias atuais, quando, após a extinção da escola, a decadência e o abandono são as marcas das antigas edificações militares do bairro. Também são assinalados o funcionamento da Fábrica de Cartuchos e a criação de duas grandes áreas militares, a Vila Militar de Deodoro e o Campo dos Afonsos. Por fim, são levantadas as perspectivas e ações do Exército brasileiro e de outros órgãos da sociedade na preservação do patrimônio e da memória da antiga escola.

Os usos sociais do corpo na praia carioca do Pêpê

Marcelo Fernando Leite Braga

Defesa: 22/03/2010 - Mestrado Profissional

Banca: Helena Maria Bomeny (orientadora), Bianca Freire Medeiros

(CPDOC/FGV), Gisele Silva Araújo (UNIRIO - PUC-RJ), Christiane Jalles de Paula (CPDOC/FGV).

Resumo: A pesquisa consiste em um trabalho de campo um uma praia do Rio de Janeiro, a "Praia Carioca do Pepê", e teve como motivação perceber, 
pelos depoimentos dos usuários, a forma como valorizam a estética do corpo. A Praia do Pepê é um dos espaços conhecidos na região das praias como aquele onde jovens saudáveis e de corpos "sarados" se encontram e mantêm relações de interação mais frequentes. De que maneira os corpos traduzem, no grupo que frequenta a praia, gostos, critérios de consumo, estilos de vida e hábitos de classe. Com o estudo de campo, procurou-se captar as representações que os indivíduos fazem de seus corpos e averiguar se é possível falar de um imaginário social do "corpo".

Patrocínios culturais incentivados: porquês, para quem e como - Oi Futuro: um estudo de caso

Guilherme de Souza Leal de Oliveira

Defesa: 22/03/2010 - Mestrado Profissional

Banca: Fernando Lattman-Weltman (orientador), Gisele Sanglard (COC-Fiocruz), Mônica Almeida Kornis (CPDOC/FGV), Lúcia Lippi de Oliveira (CPDOC/FGV).

Resumo: Este trabalho consiste em um estudo de caso sobre os patrocínios culturais incentivados realizados por uma organização da iniciativa privada que não tem a cultura como seu negócio-fim. Sua proposta é oferecer uma visão do papel desta empresa, dos motivadores para que exerça responsabilidade social utilizando a cultura, do processo de escolha dos projetos patrocinados e dos critérios que norteiam a opção por cada um deles. A pesquisa utilizou como base a análise de editais de patrocínio de diversas empresas, dados estatísticos acerca das características dos projetos inscritos e aprovados no processo da instituição escolhida e entrevistas com os protagonistas deste processo. Para contextualizar o estudo, é traçado um panorama histórico da atuação do Estado brasileiro na área cultural, através de suas políticas públicas e, principalmente, das leis de incentivo à cultura. Como fundamentação teórica, conceitos como cultura, política cultural e responsabilidade social são explorados, assim como a importância de indicadores como ferramentas de trabalho e a distinção entre mecenato e patrocínio.

Sociabilidade homoerótica masculina no Rio de Faneiro na década de 1960: Relatos do Fornal O Snob

Rogério da Silva Martins da Costa

Defesa: 22/03/2010 - Mestrado Profissional

Banca: Maria Celina Soares D’Araújo (orientadora), Sérgio Luis Carrara (IMS/UERJ), Helena Maria Bousquet Bomeny (CPDOC/FGV), João Marcelo Ehlert Maia (CPDOC/FGV). 
Resumo: Este trabalho estuda uma rede de sociabilidade homoerótica na cidade do Rio de Janeiro, na década de 1960, através da análise dos relatos contidos no jornal doméstico - produzido por um dos grupos e que circulava entre os participantes da rede $-O S n o b$. A rede era composta por vários grupos de convivência que se vinham formando desde a década de 1950, e a maioria dos participantes elaborava suas identidades pessoais compartilhando com a sociedade maior a crença de que pertenceriam ao "terceiro sexo", "sofrendo" inversão sexual.

Assim se desenvolveu uma forma de sociabilidade peculiar, caracterizada por encontros festivos em domicílios como estratégia de sobrevivência, visto que as expectativas sociossexuais dos grupos eram envoltas em hostilidade da sociedade maior. Dessa maneira, esse estudo aponta processos de sociabilização empreendidos pela rede, moldados na invisibilidade, configurando-se, ainda que de maneira não articulada (ou involuntária), em experiência de conquistas dos direitos civis e sociais, ao promover ações práticas que possibilitavam encontros de seus membros e que podem ser traduzidas como o direito de ir e vir, o direito de livre expressão, ainda que num espaço segregado (ou segredado?), direitos básicos, que, no entanto, não eram garantidos aos participantes da rede. Evidencia, nessa trajetória, os processos de ressignificação identitária que os grupos vivenciaram ao longo do período estudado.

\section{Imagens da escola: a informática educativa no Colégio Pedro II}

Sandra Silva Costa

Defesa: 23/03/2010 - Mestrado Profissional

Banca: Helena Maria Bousquet Bomeny (orientadora), Clarice Peixoto (UERJ), Raquel Emerique (CPDOC/FGV), Américo Oscar G Freire (CPDOC/FGV).

Resumo: Esta dissertação se propõe responder a uma questão específica: como uma área que propõe uma nova cultura escolar acontece e se estabelece em uma escola secular e com forte tradição humanística? Orientada pelas idéias e escritos do pesquisador, filósofo e teórico chileno José Joaquin Brunner, busquei reflexões sobre a transformação social contemporânea advinda da aproximação da educação com as novas tecnologias da informação e comunicação. Para registrar personagens relevantes e a inserção de práticas culturais centradas no uso das tecnologias da informação e comunicação, em diferentes espaços e tempos da escola, centradas no uso das tecnologias da informação e comunicação, optou-se pela investigação realizada com recursos e instrumentos audiovisuais. A partir dos depoimentos de pessoas que participaram direta e indiretamente da implantação dessa nova área dentro do Colégio Pedro II, apresentamos como parte da pesquisa um documentário de 26 minutos - Imagens da Escola: A Informática Educativa no 
Colégio Pedro II -, composto por três blocos: Primeiros Movimentos, Espaços e Bandeiras e Informática Educativa, espaço em construção

História do turismo em Petrópolis entre 1900 e 1930

André Barcelos Damasceno Daibert

Defesa: 24/03/2010 - Mestrado Profissional

Banca: Celso Corrêa Pinto de Castro (orientador), Giancarlo Moser

(FAE-Blumenau), Bianca Freire de Medeiros (CPDOC/FGV), Luciana

Quillet Heymann.

Resumo: O presente trabalho pretendeu analisar de que forma se originou a construção da chamada "natureza turística" da cidade de Petrópolis, através de uma perspectiva histórica. Como objetivo específico, pretendi descrever como se deu a organização da atividade turística no município, buscando compreender e identificar as principais narrativas e imagens que sustentam essa construção cultural, destacando as suas origens entre os anos de 1900 e 1930. Com este fim, o trabalho apresenta as origens e evolução da cidade de Petrópolis desde os antecedentes de sua fundação no século XIX. Em seguida, trabalhei no sentido de desvendar as transformações sociais no ato de viajar, na perspectiva de compreender as origens e consolidação da atividade turística organizada no município. Finalmente, analisei algumas narrativas e imagens que representam a construção cultural da "natureza turística" de Petrópolis, tendo como referência as primeiras décadas do século XX. O estudo foi realizado através de recurso a literatura técnico-científica existente e também de pesquisa documental e iconográfica que retratasse narrativas e imagens do turismo em Petrópolis no início de sua organização. Para isso, foram selecionados guias e revistas publicados entre os anos de 1900 e 1930.

\section{História e Memória do Arquivo Central da FGV \\ Maria Leonilda Reis da Silva \\ Defesa: 30/03/2010 - Mestrado Profissional}

Banca: Letícia Borges Nedel (orientadora), Célia Maria Leite da Costa (MIS), Luciana Quillet Heymann (CPDOC/FGV), Angela Maria de Castro Gomes (CPDOC/FGV).

Resumo: A presente dissertação tem por objetivo a reconstrução da trajetória institucional do Arquivo Central da Fundação Getulio Vargas, desde o momento de sua criação, em 1973, até sua transformação em Núcleo de Documentação da FGV, em 2009. Com base em documentos textuais e orais, e operando com os conceitos de memória, arquivo, documento e lugar de memória, 
são investigadas as posições ocupadas pelo arquivo dentro do contexto histórico, político e cultural em que se desenvolveu a arquivologia brasileira, a partir da década de 1930, bem como as razões que levaram à sua reestruturação, em 2009.

Mostra Sesc Cariri de Cultura: a aldeia como política para o desenvolvimento cultural local

Sidnei Moreira Cruz

Defesa: 11/05/2010 - Mestrado Profissional

Banca: Fernando Lattman-Welttman (orientador), Lia Calabre de Azevedo (Fundação Casa de Rui Barbosa), Mariana Cavalcanti Rocha dos Santos (CPDOC/FGV)

Resumo: A dissertação toma como objeto de pesquisa a Mostra SESC Cariri de Cultura, projeto cultural realizado na cidade do Crato, no sul do Ceará, região conhecida como Cariri. $\mathrm{O}$ foco está centrado na primeira década do projeto (1999-2008), na evolução do formato inicial até chegar à atual configuração, estruturalmente complexa e com caráter multicultural, abrangendo uma diversidade de manifestações artísticas e culturais, se expandindo territorialmente ao ponto de envolver 12 cidades. Esse modelo - que envolve toda uma região, fazendo convergir interesses tanto dos moradores locais os espectadores, quanto do comércio e serviços, a administração das cidades - me levou à ideia de aldeia, daí o título e a hipótese da dissertação: "Mostra SESC Cariri de Cultura: a aldeia como política para o desenvolvimento cultural local”. O conceito de aldeia foi criado para dar conta da necessidade de articulação entre a produção local e a produção nacional, por meio de um programa de intercâmbio capaz de criar um ambiente de concentração de atividades culturais aglutinadas sob a forma de mostras ou feiras. A aldeia é um conceito operacional de territorialidade que conjuga espaço, desenvolvimento econômico e cultural, organização comunitária e mercado de bens culturais. Parti de uma questão básica: como potencializar as políticas culturais públicas e privadas no sentido de contribuir para a regularização, fomento, distribuição e acesso de bens culturais para a coletividade em territórios culturais locais? Essa é uma questão que todo gestor cultural necessariamente elabora ao confrontar e relacionar desenvolvimento e cultura. Temas como planejamento, programação, parcerias, diversidade cultural, gestão da afetividade e comunidade, entre outros valores, são conjugadas em escalas variadas e não subordinadas ou dependentes, na perspectiva de perceber os graus de envolvimento e influência desses elementos e valores para o desenvolvimento local. 
Políticas de ação afirmativa para negros no governo Fernando Henrique Cardoso (1995-2002)

Marilene de Paula

Defesa: 08/042010 - Mestrado Profissional

Banca: Maria Celina Soares D'Araújo (orientadora), Dulce Chaves Pandolfi

(CPDOC/FGV), João Feres Júnior (IUPERJ), Bianca Freire de Medeiros (CPDOC/FGV).

Resumo: O presente trabalho busca, através da análise da conjuntura política das relações raciais no Brasil no final dos anos 1990 e início dos anos 2000, apontar para o surgimento de um campo específico das políticas públicas: a promoção da igualdade racial. Para obter tal finalidade, analiso a trajetória das políticas de ação afirmativa do governo Fernando Henrique Cardoso (1995-2002), desenvolvidas em vários Ministérios - tais como Justiça, Desenvolvimento Agrário, Educação, Relações Exteriores e Trabalho - e também no Supremo Tribunal Federal. Minha preocupação, através dessa análise, é determinar qual a contribuição e significado de tais políticas e do discurso político-simbólico desse governo para o avanço do debate sobre as relações raciais no Brasil.

Eletrobrás: o embate por trás de sua criação

Willian de Miranda Barreto

Defesa: 26/08/2010 - Mestrado Profissional

Banca: Matias Spektor (orientador), Marly da Silva Motta ( CPDOC/FGV), Renaut Michel Barreto e Silva (IPEA), Paulo Roberto Ribeiro Fontes (CPDOC/FGV).

Resumo: O trabalho analisa a crise do setor de energia elétrica brasileiro no início dos anos 1950 e os projetos de caráter nacionalistas elaboradas pela Assessoria de Getúlio Vargas para solucioná-la. Um dos projetos mais debatidos foi o que propunha a criação da Eletrobrás, empresa estatal que seria responsável pelos investimentos públicos na construção de novas usinas hidrelétricas. Esse projeto, que levou oito anos para ser aprovado, enfrentou forte oposição de grupos presentes em diversos segmentos da sociedade que, baseados em pressupostos liberais, eram contrários à intervenção do Estado na economia. A pesquisa analisa a atuação de alguns dos atores envolvidos no debate do projeto, a insatisfação da população, as consequências do racionamento ocorridos no período do segundo governo Vargas, a atuação do grupo estrangeiro Light e seus esforços para a manutenção do monopólio natural do setor, a atuação das empresas estaduais de energia elétrica, bem como as emendas e propostas de projetos alternativos ao que propunha a criação da Eletrobrás. 
O Fluminense Foot-ball Club: A construção de uma identidade clubística no futebol carioca (1902-1933)

Renato Lanna Fernandez

Defesa: 29/03/2010 - Mestrado Acadêmico

Banca: Carlos Eduardo Sarmento (orientador), Victor Andrade Melo

(IFCS-UFRJ), Paulo Roberto Ribeiro Fontes (CPDOC/FGV), Bernardo

Borges Buarque de Hollanda (CPDOC/FGV).

Resumo: Este trabalho tem por objetivo levantar explicações sobre a formação da identidade do Fluminense como clube que tem como marca principal a elitização calcada na distinção e no refinamento. Pretendemos analisar a história do clube durante os anos iniciais do desenvolvimento do futebol na cidade do Rio de Janeiro e sua relação com as outras agremiações futebolísticas, levantando aspectos peculiares de sua história que foram fundamentais na construção dessa imagem. Tendo como pressupostos teóricos os trabalhos de Bourdieu sobre a distinção e de Hobsbawm e Ranger sobre a invenção das tradições, procuramos demonstrar como escritores como Mario Filho e Paulo Coelho Netto foram responsáveis pela consolidação de uma série de valores simbólicos e tradições que associaram o Fluminense a um espaço de distinção e refinamento que se perpetuou historicamente.

Estação da memória: um estado das entidades de preservação ferroviária do Estado do Estado do Rio de Faneiro

Lucina Ferreira Matos

Defesa: 30/03/2010 - Mestrado Acadêmico

Banca: Paulo Roberto Fontes (orientador), Luciana Quillet Heymann (CPDOC/FGV), Marco Aurélio Santana (UFRJ), Letícia Borges Nedel (CPDOC/FGV).

Resumo: Esta pesquisa trata da memória, tendo como campo de observação as entidades de preservação ferroviária como organizações civis juridicamente constituídas que cobram do poder público a preservação da memória ferroviária. No levantamento inicial, foram identificadas 16 entidades, das quais foram selecionadas duas para aprofundamento da análise: a Associação Fluminense de Preservação Ferroviária e o Movimento de Preservação Ferroviária, ambos sediados na cidade do Rio de Janeiro. A proposta é demonstrar como esses grupos se estruturam em torno dessa memória. Aprofundo o debate sobre a consolidação desse conceito como categoria instituída e proponho sua reconstrução à luz dos debates atuais. Abordo em maior detalhe duas maneiras pelas quais os grupos entendem preservar a memória ferroviária: a operação de trens turísticos e o patrimônio cultural. Para alcançar seus objetivos, esses grupos 
usam diversas estratégias que vão da inclusão da comunidade à denúncia aos órgãos responsáveis pelo patrimônio da União até mesmo do direito à preservação da memória ferroviária pelo Estado. Há nesses grupos a participação de figuras políticas e acadêmicas que contribuem umas com as outras. Uma das hipóteses é que a extinção da RFFSA intensificou a criação dessas entidades sob a justificativa da perda da identidade do trabalhador ferroviário. Utilizo o método de observação participante, da história oral e da internet - ferramenta comum na divulgação e armazenamento de dados desses grupos. Os referenciais teóricos estão representados nos debates sobre memória, patrimônio cultural e industrial, movimentos sociais, museus e turismo. E concluo que as entidades são exemplos das formas como a sociedade civil se organiza perante a instituição política. As entidades do Rio contribuem para a preservação de uma parcela daquilo que pode representar uma dada memória ferroviária.

Batalha pela Democracia: 1961-1964. Outras visões, os sargentos e o governo foão Goulart

Stefan Freitas dos Santos

Defesa: 31/03/2010 - Mestrado Acadêmico

Banca: Maria Celina D’Araújo (orientadora), Carlos Fico (UFRJ), Mário Grynszpan (CPDOC/FGV), Américo Oscar Freire (CPDOC/FGV).

Resumo: O presente trabalho propõe debater o papel dos chamados praças das Forças Armadas, sargentos, cabos e suboficiais, durante o governo João Goulart e sua luta pelo exercício da cidadania, em uma instituição baseada na hierarquia e disciplina. Partindo da ideia clássica de cidadania proposta por T. H. Marshall e sua divisão em direitos civis, políticos e sociais, situo os praças nesse contexto e analiso o comportamento dúbio da oficialidade quanto à quebra da hierarquia. Em outras revoltas militares - como as dos tenentes em 1922 e 1924, e as sublevações de Jacareacanga (PA), em 1956, e de Aragarças (GO) em 1959 promovidas por oficiais, eles foram punidos, mas posteriormente anistiados, sem prejuízo para as suas carreiras, ao contrário dos praças, que foram expulsos das Forças Armadas após o golpe de Estado de 1. ${ }^{\circ}$ de abril de 1964.

\footnotetext{
De "forasteiro" à unanimidade: a interventoria de Furacy Magalhães na Bahia (1931-1934)

Ana Luíza Araújo Caribé de A. Pinho

Defesa: 09/04/2010 - Mestrado Acadêmico

Banca: Dulce Chaves Pandolfi (orientadora), Angela Maria de Castro Gomes (CPDOC/FGV), Antonio Luigi Negro (UFBA), Christiane Jalles de Paula (CPDOC/FGV).
} 
Resumo: Esta dissertação tem como foco a política baiana na primeira metade dos anos 1930. A análise é centrada na figura de Juracy Magalhães, que ocupou a interventoria da Bahia de agosto de 1931 a outubro de 1934, quando foi eleito, de forma indireta, governador do estado. O objetivo principal deste trabalho é identificar que estratégias adotadas por Juracy Magalhães permitiram que, em um curto espaço de tempo, o tenente cearense assumisse o controle político da Bahia. Ou seja, entender como o militar cearense, considerado um forasteiro na Bahia, conseguiu se transformar numa das mais importantes lideranças políticas do estado.

Revista do Patrimônio: editor, autores e temas

Cíntia Mayumi de Carli Silva

Defesa: 26/08/2010 - Mestrado Acadêmico

Banca: Angela Maria de Castro Gomes (orientadora), Lúcia Lippi Oliveira (CPDOC/FGV), Regina Maria do Rego Monteiro (UNIRIO), Américo Oscar Freire (CPDOC/FGV).

Resumo: Esta dissertação investiga a trajetória da Revista do Patrimônio, a principal publicação do Serviço do Patrimônio Histórico e Artístico Nacional - Sphan, entre 1937 e 1967, período que corresponde à gestão do primeiro diretor do órgão, Rodrigo Melo Franco de Andrade. Editada desde 1937, esse periódico aglutinou um grupo de intelectuais que construiu o campo do patrimônio no Brasil, tendo como protagonista o próprio Sphan. Desse modo, a Revista do Patrimônio é tomada como objeto e, simultaneamente, como fonte primordial desta pesquisa, que a considera um lugar de sociabilidade desses intelectuais que colaboraram com a preservação do patrimônio. Assim, Rodrigo M. F. de Andrade, que também era o editor das publicações do órgão, é tido como o articulador das redes que ali se encontraram e que contribuíram com o processo de constituição do campo do patrimônio, que teve na Revista um dos meios empregados para se construir e se divulgar.

Praia do Flamengo, 132 - memória, reparação e patrimonialização da União Nacional dos Estudantes

Aline dos Santos Portilho

Defesa: 09/04/2010

Banca: Mario Grynszpan (orientador), Luciana Quillet Heymann

(CPDOC/FGV), Maria Paula Nascimento Araújo (IFCS/UFRJ), Christiane Jalles de Paula (CPDOC/FGV). 
Resumo: O presente trabalho visa analisar o processo de patrimonialização da União Nacional dos Estudantes, promovido na articulação de memória e reparação, mobilizando elementos do passado da instituição, especialmente os eventos ocorridos no antigo prédio de sua sede, conhecido hoje como "terreno da UNE", na Praia do Flamengo, 132. Tem como objetivo entender como os militantes, no quadro geral de busca por reverter um processo de esvaziamento de capital político da instituição, promovem a reconversão de seu capital simbólico, mais amplo, em capital político, mais específico, potencializando-a novamente no campo político. Decorrente disso se identifica um processo a que foi nomeado patrimonialização da UNE, ou seja, a ação de reconhecê-la como elemento pertencente à retórica do patrimônio cultural brasileiro. Buscou-se adotar uma abordagem diacrônica e sincrônica. No primeiro momento, foi preciso dar conta das ações da entidade estudantil, que tiveram lugar no "prédio da UNE" ao longo do tempo para, posteriormente, perscrutar as maneiras como estes atos do passado foram recuperados e instrumentalizados no jogo político do presente. Foram analisados, primeiramente, os atos legais que envolveram o prédio/terreno, a fim de reconstruir uma história para a atuação da UNE naquele espaço. A partir desta se procurou entender os usos deste passado pelos agentes do presente, promovidos por meio da realização de projetos culturais e do processo de elaboração e instituição da Lei 12.260/2010, que reconhece a responsabilidade do Estado pelos atos ocorridos no prédio da Praia do Flamengo durante o regime militar e indeniza a instituição como forma de reparação. Assim, é na imbricação dos campos da política e da cultura que se desenvolve o processo que neste trabalho se procurou investigar.

\section{A Enciclopédia do Integralismo: lugar de memória e reformulação simbólica de um movimento (1957-1961) \\ Rodrigo Christofoletti}

Defesa: 11/08/2010 - Doutorado em História

Banca: Marieta de Moraes Ferreira (Orientadora), Mario Grinszpan (CPDOC/FGV), Rodrigo Patto Sá Motta (UFGM), Carlos Eduardo Barbosa Sarmento (CPDOC/FGV), Gilberto Grassi Calil (Unioeste Paraná).

Resumo: O ano de 1957 se tornou paradigmático para o integralismo, pois, a partir das celebrações dos 25 anos de sua criação, a intelectualidade vinculada ao movimento debruçou-se sobre sua história, o que incentivou a retomada de sua ritualidade e discurso pregressos. Isso se deu graças à insatisfação da base militante, que se viu sem identidade própria em finais dos anos 1950. Com o intuito de promover atividades que ensejassem a partilha de sua cultura política, calcada em uma rede de sociabilidade, o integralismo avançou nas suas investi- 
das, projetando estratégias e eventos que viabilizassem uma reviravolta na sua atuação político-partidária. A publicação da Enciclopédia do Integralismo e a celebração dos 25 anos de sua existência política (marcos reguladores/ lugares de memória e de construção de sua cosmogonia) serão aqui tratadas como pontos fundamentais para entendermos a atuação que o integralismo teve no período. Pesquisar o que propunham, qual discurso utilizavam e qual era a finalidade destas celebrações e da própria Enciclopédia do Integralismo poderá indicar quais as propostas e respostas integralistas a uma série de questões incômodas que a contemporaneidade fazia.

Relíquia e exemplo, saudade e esperança: o SPHAN e a Consagração de Ouro Preto.

Vanuza Moreira Braga

Defesa: 31/08/2010 - Mestrado Acadêmico

Banca: Lucia Maria Lippi de Oliveira (orientadora), Helena Maria Bomeny Garchet (CPDOC/FGV), Márcia Regina Chuva (UNIRIO), Luciana Quillet Heymann (CPDOC/FGV).

Resumo: Neste trabalho, investigamos a atuação do Serviço de Patrimônio Histórico e Artístico Nacional (SPHAN), na cidade de Ouro Preto em Minas Gerais, desde a sua criação em 1937 até o início dos anos 1960. Para este fim, observamos a atuação de seus dirigentes, Rodrigo Melo Franco de Andrade, diretor geral, e Sylvio de Vasconcellos, representante regional. Para compreender a atenção que a cidade recebeu desta instituição ao longo deste período, procuramos investigar como e por quem foram construídos os discursos que deram à antiga capital de Minas um lugar especial na memória nacional. Esta pesquisa nos levou ao final do século XIX, quando Ouro Preto perde a posição da capital do estado e historiadores e políticos locais começam a reinventar a sua história, reivindicando sua preservação. Esses discursos se pautaram na valorização dos acontecimentos políticos e artísticos que ocorreram na cidade durante o século XVIII e que representariam o marco inicial da formação de nossa nacionalidade e exemplo de civilização a ser seguido pelo resto do Brasil. Décadas mais tarde, seus descendentes, em posições de liderança no Serviço de Patrimônio, iriam se esforçar para cumprir a missão herdada, focando sua atenção na preservação e consagração da antiga Villa Rica como a maior relíquia da nação e bem comum a todos os brasileiros.

Comida de roça: culinária rural no Vale do Paraíba Fluminense Joana Muller de Carvalho 
Defesa: 30/08/2010

Banca: Celso Castro (orientador), Valter Sinder (PUC-RIO), Letícia Borges Nedel (CPDOC/FGV), Lucia Maria Lippi de Oliveira (CPDOC/FGV).

Resumo: Este trabalho tem o objetivo de definir o que é a "comida de roça" no Vale do Paraíba Fluminense e buscar os sentidos em que é empregada pela população local. O termo é usado para classificar um tipo de alimentação ligado ao mundo rural, com origem nos primeiros fluxos de colonização da região no século XVIII, associado aos hábitos de sociedades indígenas locais. Empregado por grande parcela da população, é um sistema alimentar ainda protagonizado por antigas cozinheiras, caçadores, pescadores, pequenos agricultores, ex-colonos e descendentes de escravos, que foram entrevistados de acordo com a metodologia da história oral entre 2006 e 2010. Os entrevistados revelaram uma forte memória e utilização destes hábitos ligados ao século XX e suas entrevistas apontam para uma série de transformações que a extração dos recursos naturais e o trabalho na roça sofreram neste século. Dessa forma, o trabalho identifica especificidades da composição culinária do Vale do Paraíba Fluminense a partir de hábitos alimentares rurais ainda vigentes. A pesquisa visa ressaltar a necessidade da valorização patrimonial deste sistema culinário vale-paraibano, criando ferramentas para desenvolvimento de projetos culturais na região. 